\title{
JmjC-KDMs KDM3A and KDM6B modulate radioresistance under hypoxic conditions in esophageal squamous cell carcinoma
}

\author{
Catarina Macedo-Silva (1)', Vera Miranda-Gonçalves', Ana Lameirinhas (1), Joana Lencartt ${ }^{2,3}$, Alexandre Pereira ${ }^{2,3}$, \\ João Lobo ${ }^{1,4,5}$, Rita Guimarães ${ }^{4}$, Ana Teresa Martins ${ }^{4}$, Rui Henrique ${ }^{1,4,5}$, Isabel Bravo ${ }^{2}$ and Carmen Jerónimo (D) ${ }^{1,5}$
}

\begin{abstract}
Esophageal squamous cell carcinoma (ESCC), the most frequent esophageal cancer (EC) subtype, entails dismal prognosis. Hypoxia, a common feature of advanced ESCC, is involved in resistance to radiotherapy (RT). RT response in hypoxia might be modulated through epigenetic mechanisms, constituting novel targets to improve patient outcome. Post-translational methylation in histone can be partially modulated by histone lysine demethylases (KDMs), which specifically removes methyl groups in certain lysine residues. KDMs deregulation was associated with tumor aggressiveness and therapy failure. Thus, we sought to unveil the role of Jumonji C domain histone lysine demethylases (JmjC-KDMs) in ESCC radioresistance acquisition. The effectiveness of RT upon ESCC cells under hypoxic conditions was assessed by colony formation assay. KDM3A/KDM6B expression, and respective H3K9me2 and H3K27me3 target marks, were evaluated by RT-qPCR, Western blot, and immunofluorescence. Effect of JmjC-KDM inhibitor IOX1, as well as KDM3A knockdown, in in vitro functional cell behavior and RT response was assessed in ESCC under hypoxic conditions. In vivo effect of combined IOXI and ionizing radiation treatment was evaluated in ESCC cells using CAM assay. KDM3A, KDM6B, HIF-1a, and CAIX immunoexpression was assessed in primary ESCC and normal esophagus. Herein, we found that hypoxia promoted ESCC radioresistance through increased KDM3A/KDM6B expression, enhancing cell survival and migration and decreasing DNA damage and apoptosis, in vitro. Exposure to IOX1 reverted these features, increasing ESCC radiosensitivity and decreasing ESCC microtumors size, in vivo. KDM3A was upregulated in ESCC tissues compared to the normal esophagus, associating and colocalizing with hypoxic markers (HIF-1a and CAIX). Therefore, KDM3A upregulation in ESCC cell lines and primary tumors associated with hypoxia, playing a critical role in EC aggressiveness and radioresistance. KDM3A targeting, concomitant with conventional RT, constitutes a promising strategy to improve ESCC patients' survival.
\end{abstract}

\section{Introduction}

Esophageal cancer (EC) is the eighth most common cancer worldwide and the sixth most common cause of

\footnotetext{
Correspondence: Carmen Jerónimo (carmenjeronimo@ipoporto.min-saude.pt) ${ }^{1}$ Cancer Biology \& Epigenetics Group - Research Center, Portuguese Oncology Institute of Porto (Cl-IPOP), Porto, Portugal

${ }^{2}$ Medical Physics, Radiobiology and Radiation Protection Group - Research Center, Portuguese Oncology Institute of Porto (CI-IPOP), Porto, Portugal Full list of author information is available at the end of the article These authors contributed equally: Catarina Macedo-Silva, Vera Miranda-Gonçalves

Edited by I. Amelio
}

death from cancer ${ }^{1,2}$. Esophageal squamous cell carcinoma (ESCC) is the most common histological subtype ${ }^{3-5}$. Although most patients are diagnosed with a loco-regional disease, surgery remains the cornerstone of curative-intent treatment, despite the high morbidity and mortality rates $^{6,7}$. Indeed, overall 5 -year survival rates do not exceed $15-20 \%^{8}$. In addition to surgery, radiotherapy (RT) is often used as the first-line treatment of EC, both as the main therapeutic strategy or in neoadjuvant context, combined with chemotherapy, entailing similar survival rates in advanced $\mathrm{ESSC}^{7,9}$.

\section{(c) The Author(s) 2020}

(c) (i) Open Access This article is licensed under a Creative Commons Attribution 4.0 International License, which permits use, sharing, adaptation, distribution and reproduction c. in any medium or format, as long as you give appropriate credit to the original author(s) and the source, provide a link to the Creative Commons license, and indicate if changes were made. The images or other third party material in this article are included in the article's Creative Commons license, unless indicated otherwise in a credit line to the material. If material is not included in the article's Creative Commons license and your intended use is not permitted by statutory regulation or exceeds the permitted use, you will need to obtain permission directly from the copyright holder. To view a copy of this license, visit http://creativecommons.org/licenses/by/4.0/. 
Cellular hypoxia is a common feature of most solid tumors, including EC, and it has been related to therapy resistance ${ }^{10,11}$. Indeed, in oxygen deprived microenvironment, ionizing radiation (IR) has less impact on DNA damage, once is more efficiently repaired ${ }^{12}$. Hypoxia-inducible factors (HIFs) mediates tumor cells' adaptation to hypoxic microenvironment. Specifically, the HIF transcription factor is a heterodimer composed of an oxygen-dependent $\alpha$ subunit and by a constitutively expressed non-oxygen dependent $\beta$ subunit. The $\alpha$ subunit was reported to be degraded in the presence of oxygen $\left(>5 \% \mathrm{O}_{2}\right)$. Furthermore, is translocated to the nucleus to form the HIF- $\alpha / \beta$ complex, which binds to specific promoter regions in hypoxiaresponsive elements (HREs). Binding of $\mathrm{HIF}-\alpha / \beta$ to HRE results in transcriptional upregulation of target genes typically involved in cell survival, cell metabolism, proliferation, and angiogenesis ${ }^{13}$. Interestingly, in EC, HIF- $1 \alpha$ upregulation is considered a promising endogenous hypoxia biomarker ${ }^{14}$ and HIF- $1 \alpha$-mediated upregulation of carbonic anhydrase IX (CAIX) associates with poor prognosis ${ }^{11,15-19}$.

Hypoxia also modulates the epigenetic landscape, affecting DNA methylation and enzymes responsible for histone post-translational modifications ${ }^{11,20-22}$. Among the latter, histone lysine demethylases (KDM) of Jumonji C domain family (JmjC-KDMs), exhibit different methylation and histone substrates specificity ${ }^{23}$. JmjC-KDMs activity is dependent on oxygen and 2-oxoglutarate availability, as substrates $^{24}$. Interestingly, JmjC-KDMs are modulated by hypoxia, through altered activity or expression levels (a direct mechanism) or through HIF1-mediation (an indirect mechanism) ${ }^{23,25,26}$. Although several KDM subfamilies have been found upregulated in hypoxia, only some of them are direct targets of HIF- ${ }^{23}$. In particular, KDM3A and KDM6B are activated in hypoxic tumors and associated with tumor aggressiveness and progression ${ }^{23,27}$. Furthermore, these same enzymes have been suggested as promising therapeutic targets in cancer ${ }^{28-30}$. Thus, we sought to characterize the role of JmjC-KDMs activity in ESCC radioresistance, under hypoxia, aiming to improve the effectiveness of RT through JmjC-KDMs modulation.

\section{Results}

\section{Hypoxia decreases RT response in ESCC}

In both in vitro hypoxic conditions, HIF- $1 \alpha$ chemical induction with $50 \mu \mathrm{M} \mathrm{CoCl} 2$ or $0.5-1 \%$ of $\mathrm{O}_{2}$ levels, nuclear HIF- $1 \alpha$ and cell membrane CAIX expression were increased in all cell lines, although a more impressive effect was observed in Kyse-30 and OE21 cells [which did not express these proteins in normoxia $\left(21 \% \mathrm{O}_{2}\right.$ levels)] (Supplementary Fig. S1A, B).

Kyse-30 and OE21 cells survival fraction were increased in both hypoxic conditions, whereas no effect was apparent for
Kyse-410, since a radioresistant behavior comparing with the other ones (Fig. 1a and Supplementary Fig. S1C). Furthermore, $D_{0}, D_{q}$, and SF2 values were found increased in hypoxia ( $50 \mu \mathrm{M} \mathrm{CoCl}_{2}$ or $0.5-1 \% \mathrm{O}_{2}$ levels) compared with normoxia in Kyse-30 and OE21 cell lines (Supplementary Table S1). To determine whether hypoxia might regulate double strand breaks (DSB) repair, $\gamma-\mathrm{H} 2 \mathrm{AX}$ foci staining and DNA fragmentation were assessed through immunofluorescence (IF) and comet assay, respectively. Indeed, global DNA fragmentation was significantly decreased up to $24 \mathrm{~h}$ after hypoxic-induced ESCC cell lines irradiation (2 Gy) (Fig. 1b and Supplementary Fig. S2a). Moreover, both normoxia and hypoxia conditions presented $\gamma$-H2AX foci at $30 \mathrm{~min}$, although ESCC cells in hypoxia $\left(50 \mu \mathrm{M} \mathrm{CoCl}_{2}\right.$ or $0.5-1 \% \mathrm{O}_{2}$ levels) showed a notable decrease over the time (Fig. 1c), indicating lesser DNA damage and higher radioresistance. In addition, decreased apoptosis was observed for all ESCC cell lines after $24 \mathrm{~h}$ irradiation in hypoxia $(50 \mu \mathrm{M}$ $\mathrm{CoCl}_{2}$ or $0.5-1 \%$ of $\mathrm{O}_{2}$ levels) comparing with normoxia (Fig. 1d). Contrarily, cell migration capacity increased in irradiated ESCC cells under hypoxic conditions, except for Kyse-410 treated with $50 \mu \mathrm{M} \mathrm{CoCl}_{2}$ (Fig. 1e).

\section{Hypoxia modulates KDM3A and KDM6B expression in ESCC}

Remarkably, in hypoxia $\left(50 \mu \mathrm{M} \mathrm{CoCl}_{2}\right.$ or $0.5-1 \%$ of $\mathrm{O}_{2}$ levels), ESCC cells disclosed higher KDM3A and KDM6B nuclear protein expression, as well as transcript levels (Fig. 2a, b). Conversely, H3K9me2 and H3K27me3, repressive histone markers ${ }^{31}$ targeted by KDM3A and KDM6B, respectively, were found downregulated under hypoxic conditions, except for Kyse-30 (Fig. 2c). Moreover, significant HIF- $1 \alpha$ binding to tested promoter regions of KDM3A and KDM6B was observed under hypoxia conditions, corroborating HIF- $1 \alpha-J m j C-K D M s$ interaction (Fig. 2d). Nonetheless, the same was not observed for KDM6B in Kyse-30 and OE21 cells exposed to $50 \mu \mathrm{M}$ $\mathrm{CoCl}_{2}$ (Fig. 2d).

\section{IOX1 and KDM3A knockdown increases ESCC RT response}

ESCC cells treatment with $50 \mu \mathrm{M}$ of IOX1 increased H3K9me2 and slightly alter H3K27me3 levels (Fig. 3a, b), whereas decreased protein expression of KDM3A and KDM6B was also apparent in both in vitro hypoxic conditions (Fig. 3b).

Moreover, KDMs activity inhibition with $20 \mu \mathrm{M}$ IOX1, under $50 \mu \mathrm{M} \mathrm{CoCl} \mathrm{Cl}_{2}$ or $0.5-1 \%$ of $\mathrm{O}_{2}$ levels, induces decreased cell survival fraction in all ESCC cells (Fig. 3c). Concomitantly, $\mathrm{D}_{0}, \mathrm{D}_{\mathrm{q}}$ and SF2 values were decreased in hypoxia $\left(50 \mu \mathrm{M} \mathrm{CoCl}_{2}\right.$ or $0.5-1 \%$ of $\mathrm{O}_{2}$ levels) combined with IOX1, comparatively with hypoxic conditions alone (Supplementary Table S2). Interestingly, IOX1 sensitized hypoxic ESCC cells to RT [SER > 1]. Specifically, Kyse-30 under hypoxia $\left(0.5-1 \% \mathrm{O}_{2}\right.$ levels) disclosed the highest 


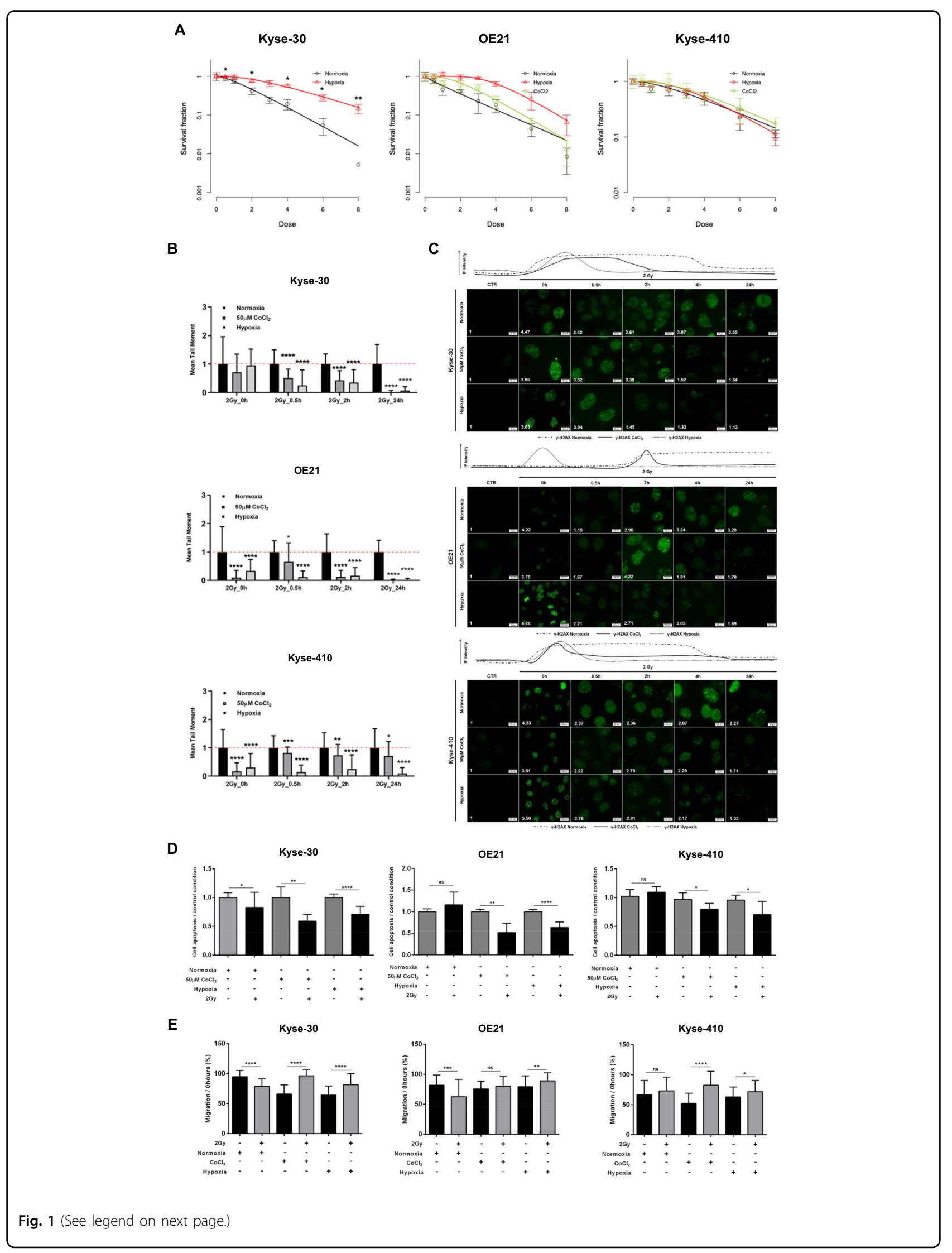


(see figure on previous page)

Fig. 1 Effect of hypoxia on RT response, DNA damage, cell migration, and apoptosis. a Cell surviving fraction in three ESCC cell lines irradiated with [0-8] Gy range concentration under normoxia, $50 \mu \mathrm{M} \mathrm{CoCl}$ and hypoxia through SHMT model analysis. Results are presented as mean \pm SD of at least 3 independent experiments. b DNA damage of 2 Gy irradiated ESCC cells between 0 and $24 \mathrm{~h}$, under normoxia, $50 \mu \mathrm{M} \mathrm{CoCl} 2$ and hypoxia by comet assay. The results are the mean of at least 50 comets per condition. All values of DNA fragmentation (tail moment) were normalized to control (OGy). Further, hypoxic conditions $\left(50 \mu \mathrm{M} \mathrm{CoCl}_{2}\right.$ or $\left.0.5-1 \% \mathrm{O}_{2}\right)$ were compared to normoxia. c Representative pictures of nuclear $\mathrm{\gamma}-\mathrm{H} 2 \mathrm{AX}$ staining of 2 Gy irradiated ESCC cells under normoxia, $50 \mu \mathrm{M} \mathrm{CoCl}$ and hypoxia conditions. All pictures were taken from Olympus IX51 microscope at $\times 400$ magnification (scale bar $20 \mu \mathrm{m}$ ). IF quantification was done using ImageJ software (version 1.6.1, from National Institutes of Health) and represented as a fold change between $2 \mathrm{~Gy}$ irradiated cells and non-irradiated control. IF, fluorescence intensity. $\mathbf{d}$ ESCC cell apoptosis under normoxia, $50 \mu \mathrm{M}$ $\mathrm{CoCl}_{2}$ and hypoxia conditions with $2 \mathrm{~Gy}$ of IR. Results are presented as mean $\pm \mathrm{SD}$ of at least three independent experiments. e ESCC cell migration through wound-healing assay, after $24 \mathrm{~h}$ of $2 \mathrm{~Gy}$ treatment normalized $0 \mathrm{~h}$. Results are the mean $\pm \mathrm{SD}$ of at least three independent experiments; Irradiated cells are compared to non-irradiated cells in each condition. ${ }^{*} p<0.05 ;{ }^{* *} p<0.01 ;{ }^{* * *} p<0.001 ;{ }^{* * *} p<0.0001$.
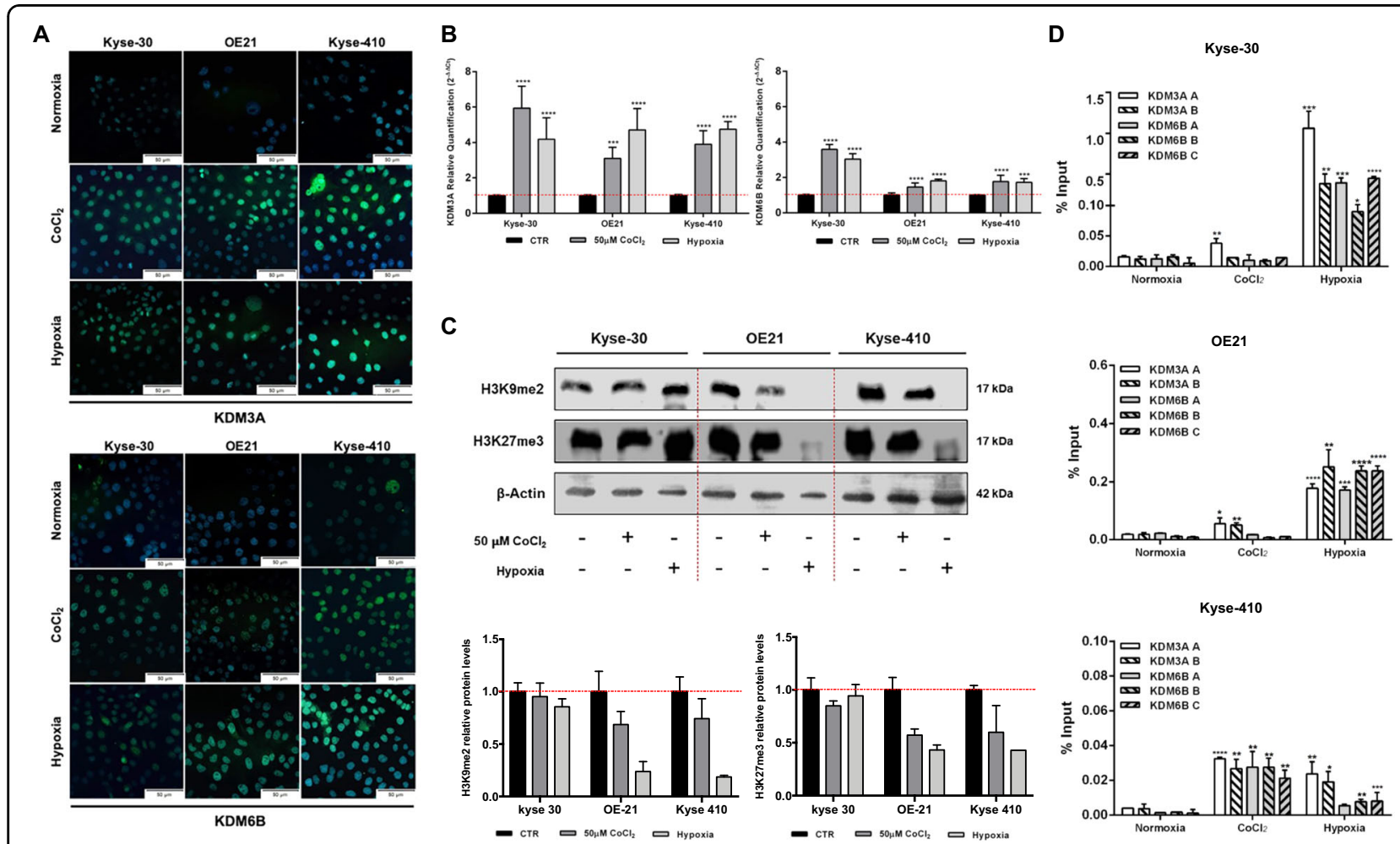

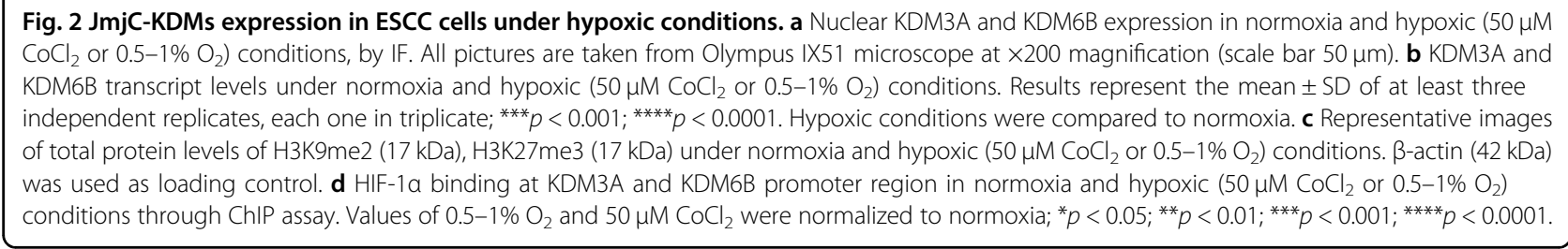

sensitization values with IOX1 treatment $(\mathrm{SER}=3.89)$ (Supplementary Table S2).

Remarkably, for all ESCC cells, IOX1 treatment combined with 2 Gy irradiation significantly increased the $\%$ of global DNA fragmentation and cell apoptosis for most of the time points, compared to $50 \mu \mathrm{M} \mathrm{CoCl}_{2}$ and $0.5-1 \% \mathrm{O}_{2}$ conditions (Fig. 3d, e and Supplementary Fig. S2B). Furthermore, cell migration capability was significantly decreased in IOX1 treated cells (Fig. 3f). Of note, $50 \mu \mathrm{M}$ IOX1 effect was significantly lower in normal esophageal Het-1A cell line than in ESCC cell lines (Supplementary Fig. S3), both for cell viability and apoptosis (Supplementary Fig. S3).

To unveil whether KDM3A is implicated in ESCC radioresponse, KDM3A knockdown (KDM3A-KD) was performed in the Kyse-410 cell line (Fig. 4). KDM3A and 
A

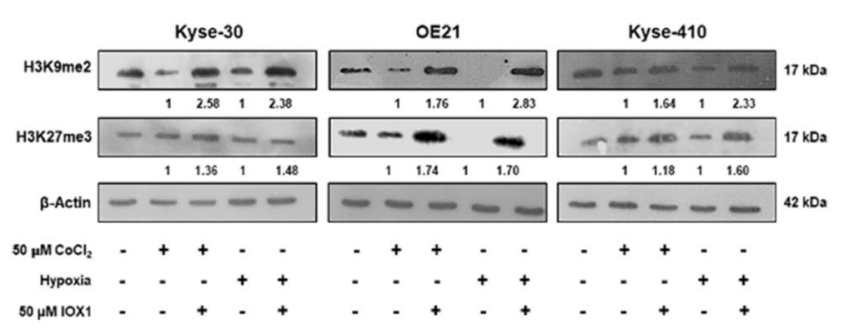

B

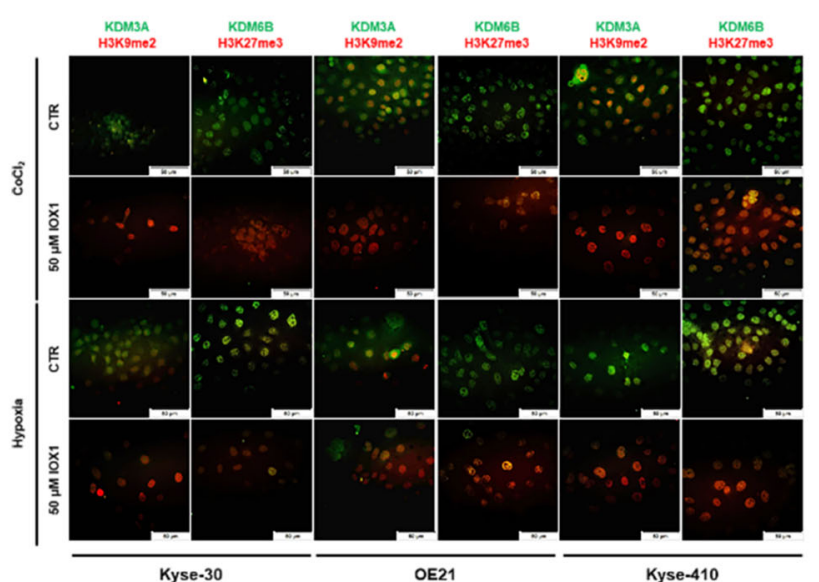

D
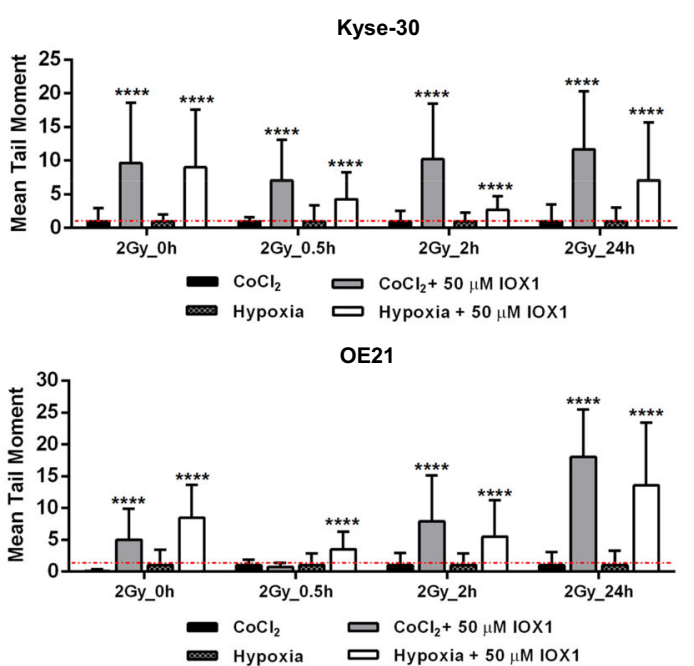

Kyse-410

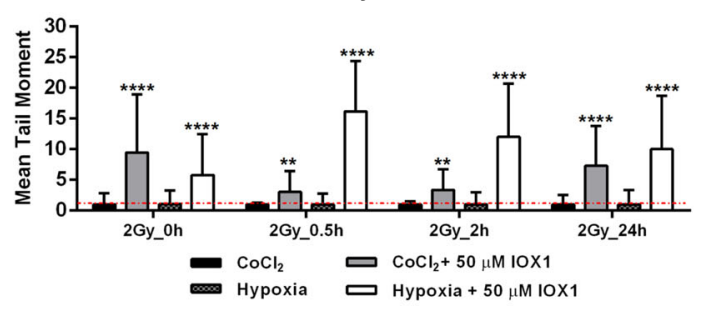

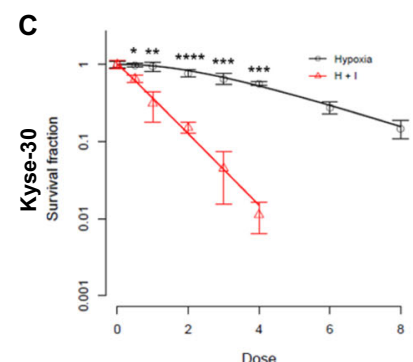
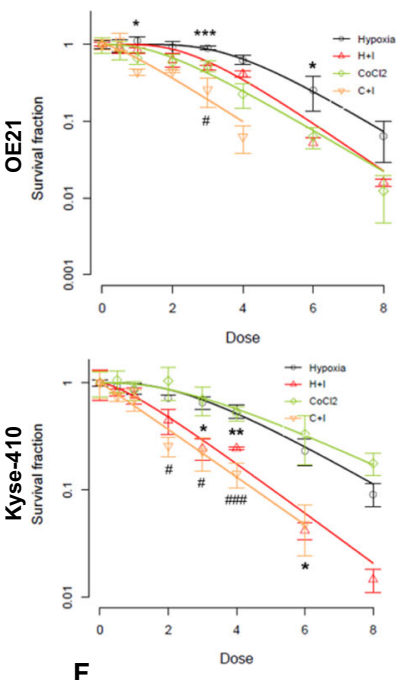

E
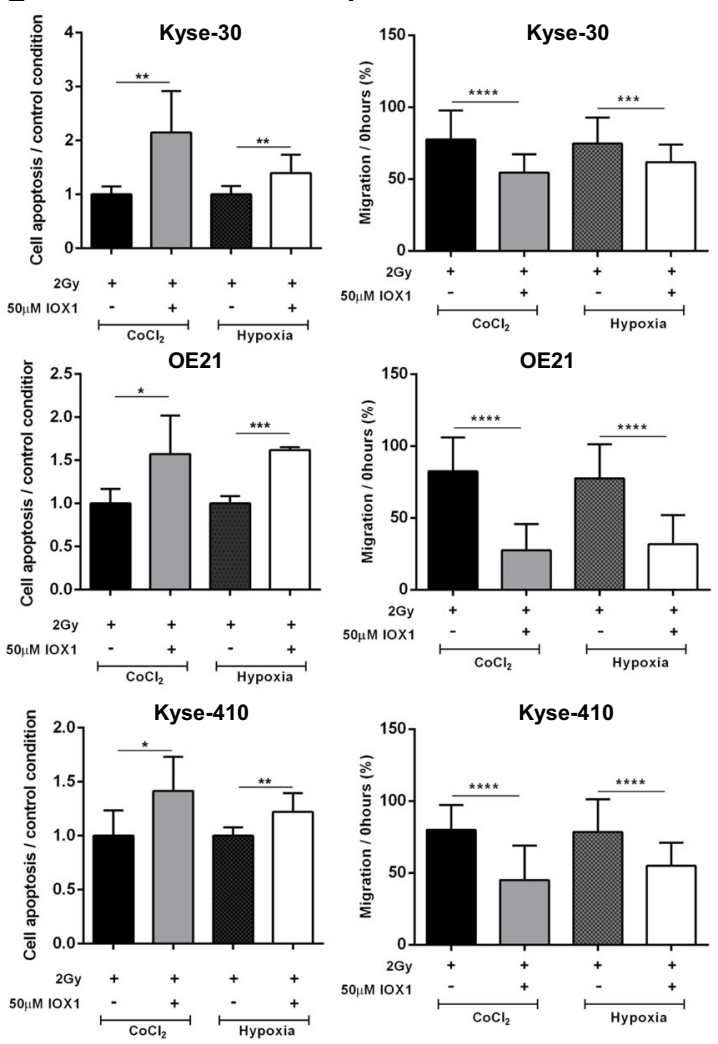

Fig. 3 (See legend on next page.) 
(see figure on previous page)

Fig. 3 JmjC-KDMs activity inhibition effect on RT response in ESCC hypoxic cell lines. a Representative images of total protein levels of H3K9me2 (17 kDa), H3K27me3 (17 kDa) with $50 \mu \mathrm{M} \mathrm{IOX1} \mathrm{JmjC-KDM} \mathrm{inhibitor} \mathrm{under} \mathrm{hypoxic} \mathrm{conditions}\left(50 \mu \mathrm{M} \mathrm{CoCl}_{2}\right.$ or $\left.0-1 \% \mathrm{O}_{2}\right)$. $\beta$-actin was used as loading control. $\mathrm{CoCl}_{2}+50 \mu \mathrm{M}$ IOX1 and hypoxia $+50 \mu \mathrm{M}$ IOX 1 were normalized to $\mathrm{CoCl}_{2}$ and hypoxia alone, respectively. A representative picture of three independent replicates was chosen. $\mathbf{b}$ Representative merged staining pictures of KDM3A and KDM6B (green fluorescence) with $\mathrm{H} 3 \mathrm{~K} 9 \mathrm{me} 2$ and H3K27me3 (red fluorescence). All pictures were taken from Olympus IX51 microscope at X200 magnification (scale bar $50 \mu m$ ). c Cell survival curves for $20 \mu \mathrm{M}$ IOX1 in combination with irradiation treatment [0-8 Gy] under hypoxic conditions $\left(50 \mu \mathrm{M} \mathrm{CoCl}_{2}\right.$ and $\left.0-1 \% \mathrm{O}_{2}\right)$. Results are presented as mean $\pm \mathrm{SD}$ of at least three independent experiments; $\left(^{*}\right)$ comparison between $20 \mu \mathrm{M}$ IOX1 + hypoxia and hypoxia alone; (\#) comparison between $20 \mu \mathrm{M} \mathrm{IOX} 1+50 \mu \mathrm{M} \mathrm{CoCl} 2$ and $50 \mu \mathrm{M} \mathrm{CoCl} 2$ alone; ${ }^{*} p<0.05 ;{ }^{* *} p<0.01 ;{ }^{* *} p<0.001 ; p<0.0001 ; \# p<0.05 ; \# \# \#<0.001$. d Effect of combined $50 \mu \mathrm{M} \mathrm{IOX1}+2$ Gy irradiation treatment in DNA damage of ESCC cells for $50 \mu \mathrm{M} \mathrm{CoCl} 2$ and hypoxia conditions by comet assay. The results are the mean of at least 50 comets per condition. Results were normalized to $0 \mathrm{~Gy}$ and combined treatment at hypoxic conditions (50 $\mu \mathrm{M}$ $\mathrm{CoCl}_{2}$ or $0-1 \% \mathrm{O}_{2}$ ) were compared to hypoxic condition alone; ${ }^{* * *} p<0.0001$. e Cell apoptosis and (f) Cell migration, for combined $50 \mu \mathrm{M}$ IOX1 + $2 \mathrm{~Gy}$ irradiation treatment under hypoxic conditions $\left(50 \mu \mathrm{M} \mathrm{CoCl} l_{2}\right.$ or $\left.0-1 \% \mathrm{O}_{2}\right)$. Hypoxic conditions $\left(50 \mu \mathrm{M} \mathrm{CoCl} \mathrm{C}_{2}\right.$ or $\left.0-1 \% \mathrm{O}_{2}\right)$ with $1 \mathrm{OX} 1$ were compared to hypoxic conditions alone. Results are represented as mean \pm SD of at least three independent experiments; ${ }^{*} p<0.05 ;{ }^{* *} p<0.01 ;{ }^{* * *} p<$ $0.001 ;{ }^{* * *} p<0.0001$.

HIF- $1 \alpha$ protein expression decreased in KDM3A-KDcompared to scramble- Kyse- 410 cells, both at baseline levels and with $50 \mu \mathrm{M} \mathrm{CoCl} 2$ or at $0.5-1 \% \mathrm{O}_{2}$ (Fig. 4a). Conversely, increased expression of nuclear KDM3Atargeted H3K9me2 was depicted in KDM3A-KD cells (Fig. 4a, b). As expected, cell survival fraction decreased within $\mathrm{CoCl}_{2}$ and hypoxic conditions in KDM3A-KD cells, simultaneously with lower $\mathrm{D}_{0}, \mathrm{D}_{\mathrm{q}}$, and SF2 values (Fig. 4c and Supplementary Table S2). Additionally, SER values higher than 1 were found in both hypoxic $(50 \mu \mathrm{M}$ $\mathrm{CoCl}_{2}$ and $0.5-1 \% \mathrm{O}_{2}$ ) KDM3A-KD. Similarly, reduced proliferation and cell migration and higher apoptosis rates were showed by KDM3A-KD cells under hypoxic $(50 \mu \mathrm{M}$ $\mathrm{CoCl}_{2}$ and $0.5-1 \% \mathrm{O}_{2}$ ) conditions after $2 \mathrm{~Gy}$ IR (Fig. $4 \mathrm{~d}-\mathrm{f}$ ), suggesting cell aggressiveness impairment. Of note, global DNA damage intensity demonstrated by comet assay (Fig. 4g and Supplementary Fig. S2C) and $\gamma-\mathrm{H} 2 \mathrm{AX}$ foci staining (Fig. 4h) remains overtime in KDM3A-KDhypoxic irradiated cells and largely diverged from scramble-hypoxic status. Together, these results indicate that hypoxic-induced JmjC-KDMs modulation promotes ESCC cells' radiosensitization, supporting KDM3A's as a key RT responsiveness mediator.

\section{KDMs activity inhibition impairs DSB DNA damage repair after ionizing radiation exposure}

To further understand whether KDMs activity inhibition with IOX1 treatment affects DNA damage repair (DDR), enriched $\gamma$-H2AX foci were found after $0.5 \mathrm{~h} 2 \mathrm{~Gy}$ IR until $24 \mathrm{~h}$ in all ESCC cells treated with IOX1, under hypoxic conditions $\left(50 \mu \mathrm{M} \mathrm{CoCl}_{2}\right.$ and $\left.0.5-1 \% \mathrm{O}_{2}\right)$, indicating increased DSBs and less DDR (Fig. 5a). Accordingly, reduced DDR effectors relative protein levels were observed in hypoxic-IOX1 ESCC treated cells after $2 \mathrm{~Gy}$ IR (Fig. 5b, c). Of note, both homologous recombination (HR) and non-homologous end-joining (NHEJ) repair pathways were disturbed (Fig. 5c). Phospho-ATM ( $\gamma$ ATM) and DNA-PKcs are common DNA damage kinases activated in response to DSBs formation in each repair pathway, HR and NHEJ, respectively ${ }^{32}$. Herein we found reduced $\gamma$-ATM and DNA-PKcs protein levels after $24 \mathrm{~h}$ of 2 Gy IR exposure in hypoxic-IOX1 treated ESCC cells compared with respective hypoxic controls, suggesting a DDR network deficiency (Fig. 5b, c). Although DNA-PKcs activation was maintained after $24 \mathrm{~h}$ of 2 Gy IR it was less pronounced in IOX1 treated cells (Fig. 5b, c). Because DNA-PKcs is known to critically interact with Ku70/80 heterodimer to signalize DDR kinase activity during classic NHEJ repair pathway we tested that in our cells ${ }^{33}$. Overall, hypoxic-IOX1 treated cells displayed less DNAPKcs activation, although subtle differences were found for Ku80 protein expression (except for Kyse-30 cells with $0.5-1 \% \mathrm{O} 2+50 \mu \mathrm{M}$ IOX1), suggesting that IOX1 did not consistently influence Ku80 expression (Fig. 5b). Conversely, NHEJ factor 1 or Cernunnos, also known as XRCC4-like factor (XLF), which is another critical core component of NHEJ repair pathway to endure gapfilling ${ }^{34}$, exhibited reduced activation in hypoxic-IOX1 treated cells compared with respective hypoxic controls, after $24 \mathrm{~h}$ of $2 \mathrm{~Gy}$ IR exposure, with the exception for kyse-410 with $50 \mu \mathrm{M}\left(\mathrm{CoCl}_{2}+\mathrm{IOX} 1\right)$ (Fig. 5b, c).

Moreover, IOX1 reduced the relative protein expression of all studied HR components (Fig. 5b, c), in accordance with NHEJ network variations. Additionally, defects on the major DDR mechanisms were more evident with IOX1 addition in hypoxic-ESCC cells (Fig. 5b, c).

Finally, IOX1 strongly reduced protein levels of both Mre11 and p95/NBS1 after 24 h of IR, suggesting a compromised DDR complex activity and further supporting previous results (Fig. 5b, c). Taken together, these findings reveal that DDR proteins hypoxic-dependent modulation after IR exposure was mainly abrogated with JmjC-KDMs activity inhibition by IOX1, in all ESCC cell lines.

\section{KDM activity inhibition decreases in vivo tumor growth and proliferation}

Overall, IOX1 combined with irradiation disclosed a more impressive effect in ESCC microtumor perimeter after $72 \mathrm{~h}$. 


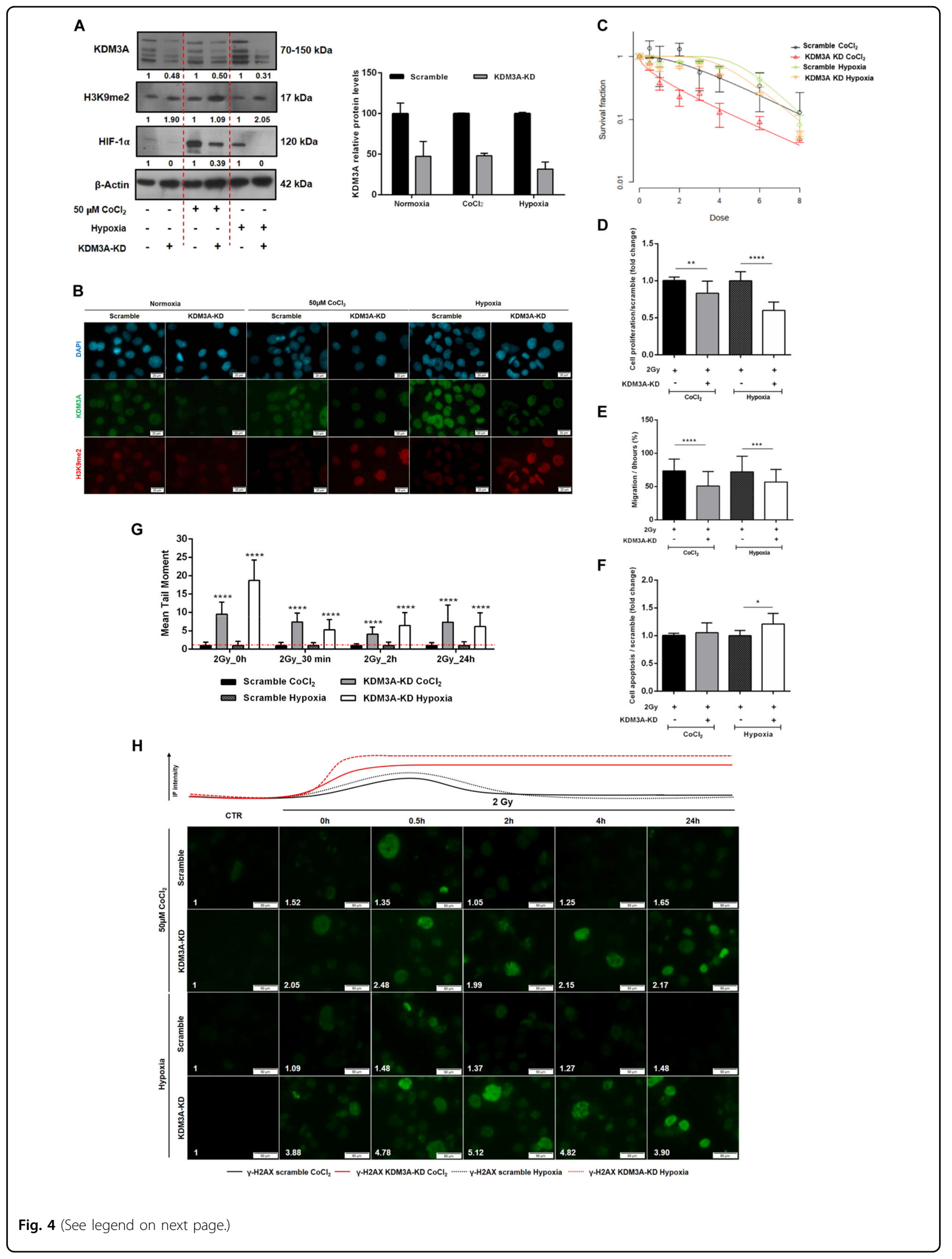


(see figure on previous page)

Fig. 4 Radiosensitizing effect of KDM3A knockdown in Kyse-410 ESCC cell line. a Representative images of total protein levels of KDM3A (70-150 kDa), H3K9me2 (17 kDa), and HIF-1a (120 kDa) in KDM3A knockdown compared with scramble under normoxia and hypoxic conditions $\left(50 \mu \mathrm{M} \mathrm{CoCl} 2\right.$ or $\left.0-1 \% \mathrm{O}_{2}\right)$. $\beta$-Actin $(42 \mathrm{kDa})$ was used as loading control. b Representative IF pictures of co-localized nuclear DAPI (blue), KDM3A (green), and $\mathrm{H} 3 \mathrm{~K} 9 \mathrm{me} 2$ (red) in KDM3A-KD and scramble, under normoxia and hypoxic conditions $\left(50 \mu \mathrm{M} \mathrm{CoCl} 2\right.$ or $\left.0-1 \% \mathrm{O}_{2}\right)$. All pictures were taken with Olympus IX51 microscope at ×200 magnification (scale bar $50 \mu \mathrm{m}$ ). c Cell survival curves from Kyse-410 KDM3A-KD/Scramble cell lines irradiated with [0-8] Gy range IR dose fraction under $50 \mu \mathrm{M} \mathrm{CoCl}$ and $0.5-1 \% \mathrm{O}_{2}$ hypoxic conditions through SHMT model analysis. Results are presented as mean \pm SD of at least three independent experiments. $\mathbf{d}$ Cell proliferation (e) $24 \mathrm{~h}$ migration normalized to $\mathrm{OH}$ and (f) cell apoptosis for combined $\mathrm{KDM} 3 \mathrm{~A}-\mathrm{KD} / \mathrm{Scramble}+2 \mathrm{~Gy}$ irradiation under hypoxic conditions $\left(50 \mu \mathrm{M} \mathrm{CoCl} 2\right.$ or $\left.0-1 \% \mathrm{O}_{2}\right)$. Fold changes were obtained after $2 \mathrm{~Gy} / 0 \mathrm{~Gy}$ normalization. Results are represented as mean \pm SD of at least three independent experiments; ${ }^{*} p<0.05 ;{ }^{* *} p<0.01 ;{ }^{* *} p<0.001 ;{ }^{* * * *} p<0.0001$. g DNA damage of $2 \mathrm{~Gy}$ irradiated Kyse-410 KDM3A-KD/Scramble cells between 0 and $24 \mathrm{~h} 50 \mu \mathrm{M} \mathrm{CoCl} 2$ and hypoxia $\left(0.5-1 \% \mathrm{O}_{2}\right)$, by comet assay. Results refer to the mean values of at least 50 comets per condition. All values of DNA fragmentation (tail moment) were normalized to control (0 Gy). Fold change of relative values KDM3A-KD were compared to control scramble. $\mathbf{h}$ Representative pictures of nuclear $\mathrm{y}-\mathrm{H} 2 \mathrm{AX}$ staining of $2 \mathrm{~Gy}$ irradiated Kyse-410 KDM3A-KD/Scramble cells (0-24 h) under $50 \mu \mathrm{M} \mathrm{CoCl}$ and hypoxia $\left(0.5-1 \% \mathrm{O}_{2}\right)$. All pictures were taken with Olympus IX51 microscope at ×200 magnification (scale bar 50 um). IF quantification was done using ImageJ software (version 1.6.1, from National Institutes of Health) and represented as a fold change between $2 \mathrm{~Gy}$ irradiated cells and non-irradiated control. IF, fluorescence intensity.

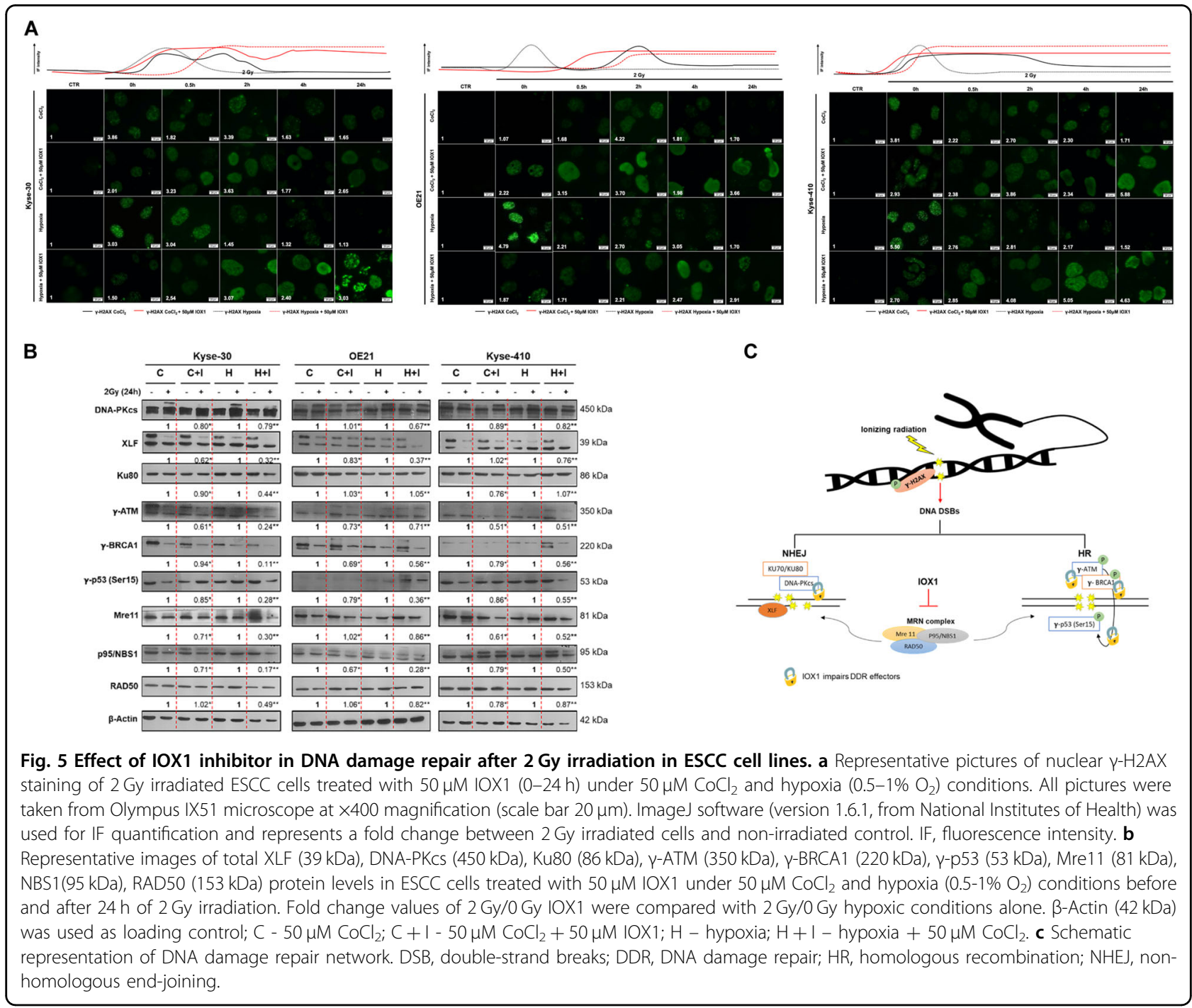




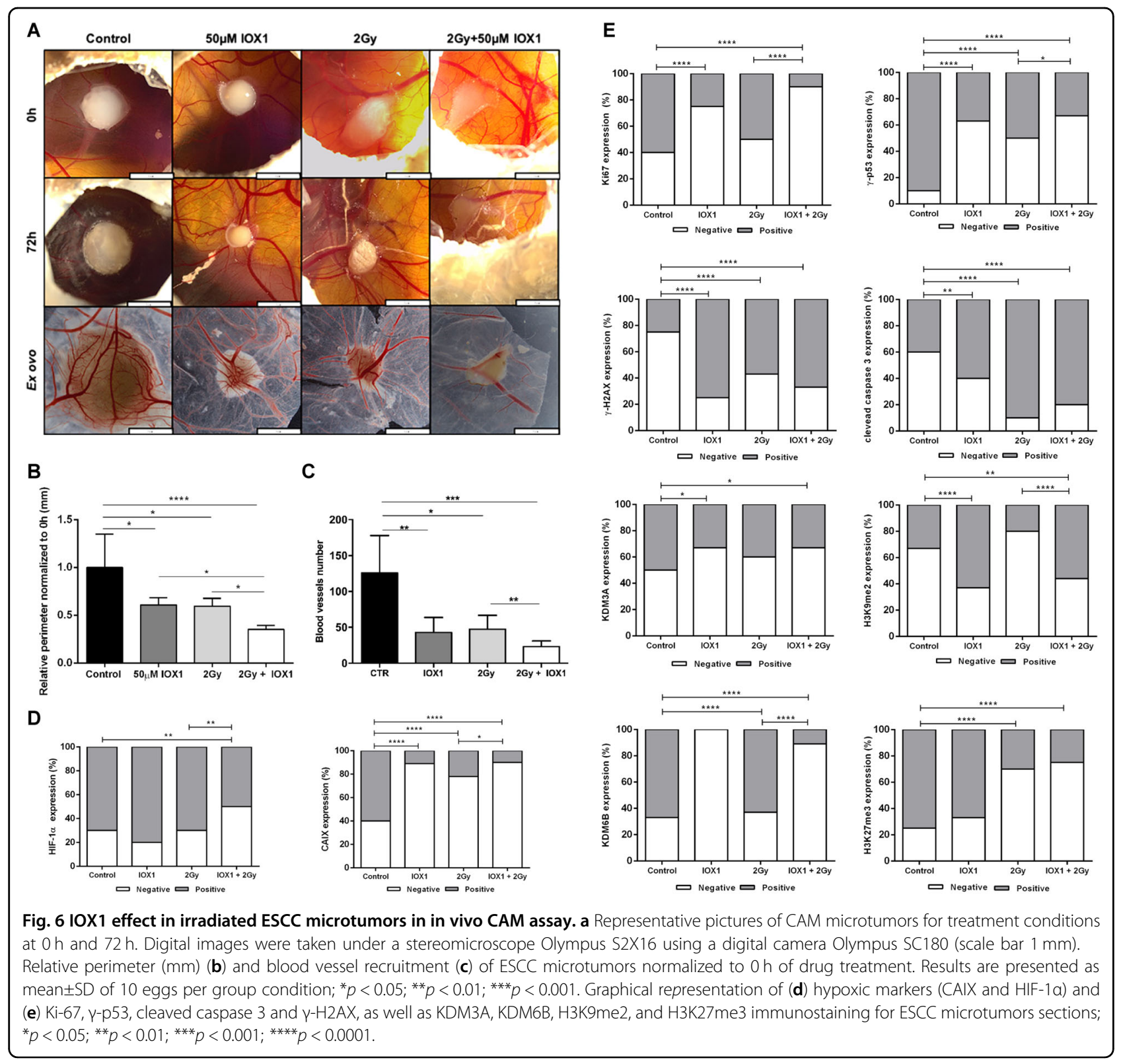

Nevertheless, a significant reduction in chorioallantoic membrane (CAM) microtumors size was also achieved with each treatment alone (Fig. 6a, b). These results were paralleled by the reduced number of blood vessels formation (Fig. 6c). Furthermore, the combined treatment led to a significant decrease in CAIX and HIF-1 $\alpha$ expression (Fig. 6d and Supplementary Fig. S4).

Additionally, an overall decrease of Ki-67 and $\gamma$-p53 expression was displayed by CAM microtumors treated with IOX1 alone or combined with radiation, compared with the respective control (Fig. 6e and Supplementary Fig. S4). Conversely, increased cleaved caspase 3 and $\gamma-$ H2AX expression was depicted by treated CAM microtumors, although no differences were apparent between tumors exposed to combined treatment or irradiated only (Fig. 6e and Supplementary Fig. S4).

Finally, KDM3A and KDM6B decreased expression was accomplished in CAM tumors treated with IOX1 inhibitor (Fig. 6e and Supplementary Fig. S4), although only H3K9me2 was significantly increased in target marks (Fig. 6e and Supplementary Fig. S4), supporting in vitro findings, and thus, indicating KDM3A as a key targetable molecule to radiosensitize hypoxic ESCC.

\section{KDM3A is overexpressed in ESCC tissues}

In tissue samples, nuclear KDM3A protein expression was significantly higher in ESCC than in normal esophagus (NE) $(67 \%$ vs $5 \%, p<0.0001)$, whereas no differences 


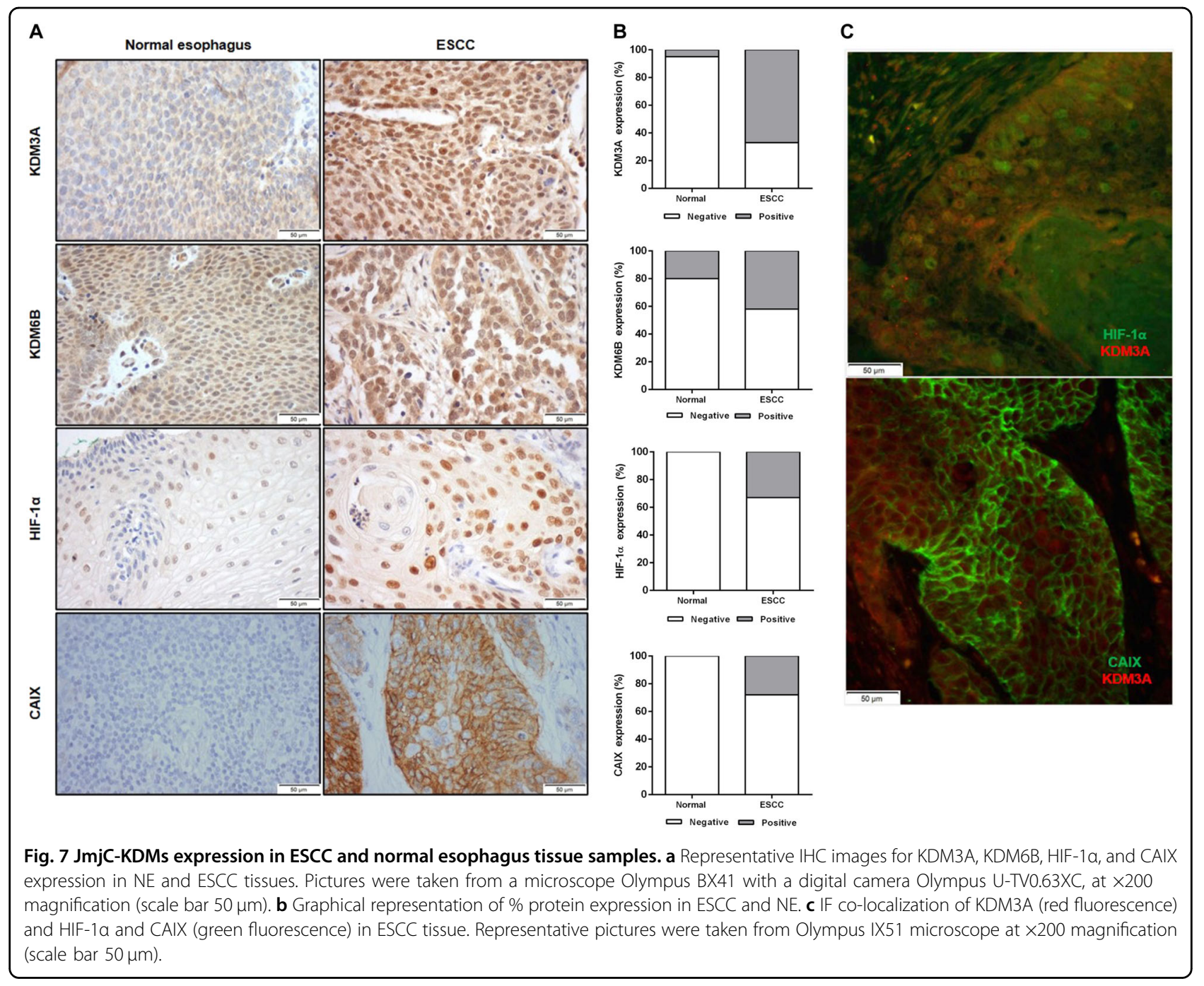

were apparent concerning KDM6B expression (42\% vs $20 \%, p=0.019$ ) (Fig. 7a, b and Table 1). Moreover, specific nuclear and cell membrane expression was observed for HIF- $1 \alpha$ and CAIX, respectively. Both HIF- $1 \alpha$ (33\% vs $0 \%, p=0.002)$ and CAIX ( $28 \%$ vs $0 \%, p=0.009)$ expression were upregulated in tumors compared to NE (Fig. 7a, $\mathrm{b}$ and Table 1).

Interestingly, a significant association between KDM3A and HIF- $1 \alpha(p=0.021)$ expression was found, although only a trend was observed regarding CAIX $(p=0.07)$ (Table 2). Indeed, in ESCC tissues, KDM3A co-localized both with HIF-1 $\alpha$ and CAIX (Fig. 7c). Nonetheless, no association was found for KDM6B and any of hypoxic markers (Table 2).

\section{Discussion}

ESCC is highly incident worldwide, entailing poor prognosis and low overall survival rates ${ }^{1,35}$, despite some
Table 1 KDMs and hypoxic markers positive expression in ESCC and normal esophagus.

\begin{tabular}{llllll}
\hline & $\boldsymbol{N}$ & KDM3A (\%) & KDM6B (\%) & HIF-1a (\%) & CAIX (\%) \\
\hline Normal & 20 & $1(5)$ & $4(20)$ & $0(0)$ & $0(0)$ \\
ESCC & 61 & $41(67)$ & $25(42)$ & $20(33)$ & $17(28)$ \\
& $p$ value & $<0.0001$ & 0.109 & 0.002 & 0.009 \\
\hline
\end{tabular}

therapeutic advances over the last years ${ }^{7,36}$. Thus, the identification of new molecular targets that might improve therapeutic efficacy for advanced ESCC is urgently needed. Hypoxia has been associated with poor prognosis in EC, namely due to resistance to RT, the gold standard therapy for advanced stages ${ }^{12,37}$. Indeed, EC patients with nonhypoxic tumors, displaying HIF-1 $\alpha$ downregulation, endure complete chemoradiotherapy response, contrary to patients 
Table 2 KDMs and hypoxic markers association in tissue cohort.

\begin{tabular}{|c|c|c|c|c|c|c|}
\hline & \multicolumn{2}{|c|}{ KDM3A (\%) } & \multirow[t]{2}{*}{$p$ value } & \multicolumn{2}{|c|}{ KDM6B (\%) } & \multirow[t]{2}{*}{$p$ value } \\
\hline & Negative & Positive & & Negative & Positive & \\
\hline \multicolumn{7}{|l|}{ HIF-1a (\%) } \\
\hline Negative & $34(42)$ & $27(33)$ & 0.021 & $41(51)$ & $20(25)$ & 0.282 \\
\hline Positive & $5(6)$ & $15(19)$ & & $10(13)$ & $9(11)$ & \\
\hline \multicolumn{7}{|l|}{ CAIX (\%) } \\
\hline Negative & $34(42)$ & $30(37)$ & 0.07 & $40(50)$ & $23(29)$ & 1 \\
\hline Positive & $5(6)$ & $12(15)$ & & $11(14)$ & $6(7)$ & \\
\hline
\end{tabular}

with high HIF- $1 \alpha$ expressing tumors ${ }^{14}$. Herein, we proved that in vitro ESCC cells under hypoxia demonstrate a decreased RT response, through a HIF-1 $\alpha$-dependent manner. Furthermore, reduced $\gamma-\mathrm{H} 2 \mathrm{AX}$ expression, lower DNA fragmentation and decreased cell death fraction was found in tumor cells under hypoxia after IR exposure.

Recently, hypoxia has been associated with epigenetic deregulation $^{21}$. Indeed, histone lysine demethylases, namely JmjC-KDMs superfamily was found to be regulated by oxygen levels and/or HIF- $1 \alpha$ transcription factor $^{38}$. Specifically, both low $\mathrm{O}_{2}$ levels and HIF- $1 \alpha$ expression were reported to induce KDM3A and KDM6B expression $^{23}$. Still, HIFs might be regulated by 2oxoglutarate-dependent members, which involves JmjCKDMs family, as well as, prolyl hydroxylases (PHD) ${ }^{23}$. Accordingly, in our hands reduced nuclear HIF- $1 \alpha$ expression levels were found in KDM3A-KD cells.

Furthermore, nuclear HIF-1 $\alpha$ expression levels were not significantly altered in IOX1 CAM-associated microtumors, whereas a significant reduction was found after 2 Gy IR and after combined treatment. This was followed by decreased tumor volume and consequently, decreased hypoxic foci. Additionally, IOX1 was also shown to have a higher selectivity for Pan-JmjC-KDMs activity inhibition than $\mathrm{PHDs}^{39}$. Indeed, a similar HIF-1 $\alpha$ expression trend in IOX1 Kyse-410 microtumors may be partially explained by intrinsic expression levels in the control condition and the apparent hypoxic foci in 3D tumors.

Additionally, findings from in vitro assays using different cell lines suggested that under hypoxic conditions, HIF- $1 \alpha$ recruits KDM3A, promoting H3K9me2 demethylation, and increasing gene transcription ${ }^{40}$. Remarkably, we showed that in ESCC cells, both KDM3A and KDM6B expression was upregulated in parallel with low oxygen levels and /or HIF-1 $\alpha$ overexpression, with the latter specifically bound to KDM3A and KDM6B promoter region under hypoxic conditions. Thus, our findings both confirm and extend previously published observations.
Additionally, several studies suggested that both KDM3A and KDM6B were putative therapeutic targets in different cancer models, not including ESCC. Indeed, KDM3A inhibition decreased estrogen receptor positive breast cancer cells' proliferation ${ }^{41}$ whereas it was implicated in stemness and chemoresistance in ovarian cancer $^{42}$. Furthermore, KDM3A targeting increased response to anti-angiogenic therapies, disclosing a role in tumor angiogenesis ${ }^{43}$ Interestingly, in vitro studies in lung and breast cancer cells demonstrated that KDM6A inhibition decreased cell survival and improved RT response, through H3K27me3 enhancement ${ }^{44}$. Furthermore, two other KDMs, KDM4C, and PHF8 were associated with ESCC malignant features. Indeed, KDM4C targeting decreased ESCC stemness properties ${ }^{45}$, whereas PHF8's inhibition promoted apoptosis and decreased ESCC cell proliferation and invasion ${ }^{46}$. Interestingly, our in vitro data we demonstrated that radioresistant phenotype observed under hypoxic conditions was abrogated with both JmjCKDMs activity inhibition and KDM3A-KD, promoting radiosensitization in ESCC cells, in line with the results obtained with IOX1 inhibitor. Of note, hypoxic-dependent KDM3A seems to play a critical role in $\mathrm{RT}$ response modulation in in vitro and in vivo experiments. Furthermore, radiosensitized hypoxic-IOX1 treated ESCC cells impaired DDR network, with decreased relative protein levels of the major DDR effectors. In the same vein and as a consequence of DNA damage repair deficiency, $\gamma-\mathrm{H} 2 \mathrm{AX}$ was independently maintained overtime after cell replication in hypoxic-induced IOX1 cells, suggesting the persistence unrepaired DNA DSBs. Remarkably, a similar function of a KDM5B inhibitor, JIB-04, was reported to radiosensitize lung cancer ${ }^{47}$. Defects in DNA repair dynamics prevents DDR resolution, due to endless $\gamma$ $\mathrm{H} 2 \mathrm{AX}$ activation and impaired recruitment of the major HR and NHEJ repair effectors ${ }^{47}$.

Those results were further supported by in vivo experiments using the CAM assay. Additionally, the reduction on microtumor aggressiveness features was 
demonstrated by reduced Ki67 expression and $\gamma$-p53 expression, thus supporting the DDR-related effectors decreased expression, while DNA DSB levels were increased, as well as cell death, with active caspase 3 and $\gamma$-H2AX overexpression. Importantly, both in vitro and in vivo experiments support the demethylating role of KDM3A as a mediator of radioresistance, since higher H3K9me2 levels were observed in IOX1 treated tumors. Interestingly, deregulation of JmjC-KDMs, including $\mathrm{LSD}^{48}$, KDM3C ${ }^{49}, \mathrm{KDM}_{4} \mathrm{C}^{50}, \mathrm{KDM}^{4} \mathrm{~B}^{46}$, and UTX/ $\mathrm{KDM}^{51} \mathrm{~A}^{51}$, has been implicated in esophageal carcinogenesis, although published data concerning KDM3A and KDM6B is notoriously lacking. Indeed, our study is the first to demonstrate that, in primary ESCC, KDM3A overexpression positively associates with the hypoxic markers, HIF-1 $\alpha$ and CAIX, further supporting the in vitro data ${ }^{40}$.

Overall, our results indicate that hypoxia induces KDM3A overexpression, conferring growth advantage to ESCC submitted to IR, highlighting its role in cancer progression and therapy resistance. Remarkably, in ESCC, KDM3A might constitute a promising therapeutic target for pharmacological inhibition in combination with neoadjuvant RT to improve ESCC patients' survival.

\section{Materials and methods}

\section{ESCC cell lines and cell culture}

For this study, three ESCC cell lines obtained from American Type Culture Collection (ATCC $®$ ), USA, were used for in vitro and in vivo assays: Kyse-30 (well differentiated), OE21 (moderately differentiated), and Kyse-410 (poorly differentiated). Additionally, for drug toxicity evaluation, a normal epithelial cell line from human esophagus, Het-1A (ATCC®) was used. Tumor cells were grown in RPMI-1640 medium (Biochrom, Merk, Germany), while normal cells were maintained in Dulbecco's Modified Eagle's Medium (DMEM 1x, GBICO, Invitrogen, USA), supplemented with $10 \%$ fetal bovine serum (FBS, Biochrom, Merk, Germany) and $1 \%$ penicillin/ streptomycin (GIBCO, Invitrogen, USA) at $37^{\circ} \mathrm{C}$ with $5 \%$ $\mathrm{CO}_{2}$ and $74 \% \mathrm{~N}_{2}$. Mycoplasma test was performed using TaKaRa PCR Mycoplasma Detection Set (Clontech Laboratories, EUA), before all experiments.

\section{Hypoxia stabilization}

Hypoxia induction was carried out for in vitro assays using airtight chambers [modular incubator chamber (MIC-101), Billups-Rothenberg, USA] saturated with 95\% $\mathrm{N}_{2}$ and $5 \% \mathrm{CO}_{2}$. ESCC cell lines were grown at $0.5-1 \%$ $\mathrm{O}_{2}$, in an incubator at $37^{\circ} \mathrm{C}$.

\section{Chemicals}

Cobalt Chloride, $\mathrm{CoCl}_{2}$ (Sigma-Aldrich, Germany) was dissolved in sterile distilled water $\left(\mathrm{dH}_{2} \mathrm{O}\right)$ at $50 \mu \mathrm{M}^{52}$.
Furthermore, 5-Carboxy-8-hydroxyquinoline (IOX1, Sigma-Aldrich, Germany), the most potent pan-histone demethylase inhibitor ${ }^{39}$, was used. This compound was dissolved in dimethyl sulfoxide (DMSO, Sigma-Aldrich, Germany) at 20 and $50 \mu \mathrm{M}$ depending on the assay.

\section{Irradiation}

IR was performed at room temperature $(\mathrm{R} / \mathrm{T})$ with normal oxygen levels, using TrueBeam linear accelerator as irradiation source within a field of $25 \times 25 \mathrm{~cm}^{2}$, a photon energy of $6 \mathrm{MV}$ and a dose rate of $600 \mathrm{MU} / \mathrm{min}$. For hypoxic experiments $\left(0.5-1 \% \mathrm{O}_{2}\right)$ cells were maintained under oxygen deprivation during all experimental timeline, before and after IR radiation exposure for all in vitro assays. Nonetheless, In vivo chicken CAM irradiation was carried out in a microSelectronv3 Iridio-192 brachytherapy (192-IrmHDR-v2r) at 2 Gy per egg/pulse for chicken embryo's protection (Image planning represented on Supplementary Fig. S5) since only a low dose rate brachytherapy was attained by the animal.

\section{RNA extraction, quantification, CDNA synthesis and RT-qPCR}

Tumor cell RNA was extracted by a ribozol reagent method. Revert Aid RT Kit (ThermoScientific Inc.) was used for cDNA synthesis, according to the manufacturer's instructions. RT-qPCR was performed in LightCycler480II (Roche) using Xpert Fast SYBER Mastermix Blue (GE22.2501, Grisp) with specific designed primers (Supplementary Table S3). GUS $\beta$ was used as endogenous control.

\section{Total protein extraction, quantification, and SDS-PAGE western blot}

For next experiments all antibodies details are described in Supplementary Table S4.

Briefly, cells were scraped in lysis Buffer (Kinexus Bioinformatics Corporation, Vancouver, British Columbia, Canada) on ice. Protein quantification was performed using the Pierce BCA Protein Kit (Thermo Scientific Inc.), according to the manufacturer's instructions. Western blot (WB) was performed as previously described ${ }^{53}$ using specific primary antibodies. After primary antibody incubation overnight at $4{ }^{\circ} \mathrm{C}$, specific conjugated horseradish peroxidase secondary antibodies (Bio-Rad, USA) were incubated $1 \mathrm{~h} R / T$. Chemiluminescence was detected with Clarity WB ECL substrate (Bio-Rad, USA) and evaluated using ImageJ software (version 1.6.1, from National Institutes of Health). $\beta$-actin served as control of the total loaded protein.

\section{Immunofluorescence and immunocytochemistry}

ESCC cells were seeded in cover slips into culture plates and fixed with $4 \%$ paraformaldehyde. For nuclear 
proteins, cells were permeabilized with $0.25 \%$ Triton X100 solution in $1 \mathrm{x}$ phosphate-buffer saline (PBS $1 \mathrm{x}$ ).

For IF, cells were blocked with $5 \%$ bovine serum albumin (BSA) (Santacruz Biotechnology, Inc, USA) in PBS 1x. Except for $\gamma-\mathrm{H} 2 \mathrm{AX}$ antibody, which was incubated for $1 \mathrm{~h}$ at $\mathrm{R} / \mathrm{T}$, all remainder antibodies (H3K9me2, H3K27me3, KDM3A, and KDM6B) were incubated overnight at $\mathrm{R} / \mathrm{T}$. Then, cells were incubated for $1 \mathrm{~h}$ at $\mathrm{R} /$ $\mathrm{T}$ with secondary antibodies, anti-rabbit immunoglobulin G (IgG) Alexa Fluor ${ }^{\mathrm{TM}} 488$ goat (A11008, Invitrogen, Thermofisher Scientific, USA) and/or anti-mouse IgG Alexa Fluor ${ }^{\mathrm{TM}} 594$ goat (A11032, Invitrogen, Thermofisher Scientific, USA) and stained with 4'6-diamidino-2phenylindole (DAPI) (AR1176, BOSTER Biological Technologies, China).

For immunocytochemistry (ICC), NovolinkTMMax Polymer Detection System (Leica Biosystems, Cat. \#RE7260K) was used. Briefly, endogenous peroxidases activity was blocked with $3 \% \mathrm{H}_{2} \mathrm{O}_{2}$, followed by non-specific linked blockage in horse serum (GIBCO, Invitrogen, USA). Primary antibody was incubated overnight at $\mathrm{R} / \mathrm{T}$ in a humidified chamber. Furthermore, cells were incubated with postprimary solution followed by polymer and 3,3'-diaminobenzidine (DAB) (Sigma-Aldrich ${ }^{\text {TM }}$, Germany), Then, cells were counterstained with hematoxylin and mounted in aqueous medium (Aquatex®, Merk, Germany).

\section{KDM3A gene knockdown}

KDM3A gene knockdown (KDM3A-KD) was performed using CRISPR-cas9 technology with a guide RNA (gRNA) sequence targeting KDM3A (GenScript, Piscataway, NJ) (Supplementary Table S3). Briefly, plasmid transfection was carried out with Lipofectamine ${ }^{\circledR} 3000$ reagent (Invitrogen, USA), following manufacturing instructions. Scramble gRNA sequence was used as negative transfection control. Transfected cells' selection was done by Puromycin at $1 \mu \mathrm{g} /$ $\mathrm{mL}$ in RPMI-1640 cell culture medium.

\section{Phenotypic assays}

IOX1 effects on cell viability were assessed by MTT assay, following previously reported procedures ${ }^{54}$. Apoptosis was evaluated after $24 \mathrm{~h}$ of $2 \mathrm{~Gy}$ IR and after $48 \mathrm{~h}$ and $72 \mathrm{~h}$ of IOX1 induction and hypoxic stimulation, respectively, using APOPercentage assay kit (Biocolor Ltd., Belfast, Northern Ireland, UK), according to manufactured instructions. Concerning wound-healing assay, wild-type (WT) ESCC cells or Kyse-410 KDM3A-KD and scramble were seeded and exposed to $50 \mu \mathrm{M} \mathrm{CoCl}{ }_{2}$ or hypoxia. Subsequently, when applicable, cells were treated with $50 \mu \mathrm{M}$ IOX1 $24 \mathrm{~h}$ before 2 Gy IR. Then, cells growth at $95 \%$ of confluence and two parallel "wounds" in each well (initial slope) were done. Then, relative migration distance was analyzed by beWound - Cell Migration Tool (version 1.5) calculating \% cell migration $=(\mathrm{A} / \mathrm{B}) / \mathrm{C}^{*} 100$
(A, width of cell wound at initial slope; B, width of cell wound at several time points; $C$, width mean of cell wound at initial slope)]. KDM3A-KD cell proliferation assay was assessed after $24 \mathrm{~h}$ of $2 \mathrm{~Gy}$ IR and $48 \mathrm{~h}$ of $50 \mu \mathrm{M}$ $\mathrm{CoCl}_{2}$ and hypoxia induction, using Cell proliferation ELISA BrdU (5-bromo-2'deoxyuridine) assay kit (Roche Applied Sciences, Penzberg, Germany), according to manufactured instructions.

\section{Colony formation}

ESCC cells were seeded in 6-well culture plates at specific concentrations for each experimental group, as detailed in Supplementary Table S1. Then, after $48 \mathrm{~h}$ of hypoxia exposure or $\mathrm{CoCl}_{2}$ addition, cells were exposed to IR and incubated at $37^{\circ} \mathrm{C}$ for 7 days. Experiments were carried out in all ESCC cell lines, whereas Kyse-30 cell line was not able to form colonies after $\mathrm{CoCl}_{2}$ chemical induction. Also, $24 \mathrm{~h}$ after hypoxia stimulation and before IR, cells were treated with $20 \mu \mathrm{M}$ IOX1. Colonies were stained with $25 \%$ (w/v) Giemsa. Colonies depicting more than 50 single cells were counted and analyzed using RAD ADAPT software (Biomedical Simulation Resource, USC, California, USA) ${ }^{55}$. Exponential single hit multi-target model (SHMT), $\mathrm{S}(\mathrm{D})=$ $\mathrm{PE} *\left[1-\left(1-\exp \left(-\mathrm{D} / \mathrm{D}_{0}\right)\right)^{\mathrm{n}}\right)$ was used. Concerning statistics, $\mathrm{D}_{0}$ represents the induction of one lethal event per cell becoming at $37 \%$ of viability, through the measurement of the ending slope resulting from a multiple event killing. Furthermore, $\mathrm{D}_{\mathrm{q}}$, quasi-threshold dose represents the width of the curve shoulder. Additionally, sensitized enhancement ratio (SER) was evaluated according to $\mathrm{D}_{0}$ (without sensitizer) / $D_{0}$ (with sensitizer). The sensitizer is IOX1 inhibitor or Kyse-410 KDM3A-KD cells.

\section{Alkaline comet assay}

ESCC cells were treated with 2 Gy IR at $0 \mathrm{~h}, 0.5 \mathrm{~h}, 2 \mathrm{~h}$, and $24 \mathrm{~h}$. Briefly, cells were re-suspended in $0.5 \%$ low melting agarose $(\mathrm{w} / \mathrm{v})$ and immediately placed on a sheet previously covered with $1 \%$ normal melting agarose $(\mathrm{w} / \mathrm{v})$. Then, a cell lysis buffer $(2.5 \mathrm{M} \mathrm{NaCl}, 100 \mathrm{mM} \mathrm{Na} 2$ EDTA, $10 \mathrm{mM}$ Tris Base, $1 \%$ Triton $\mathrm{X}-100), \mathrm{pH} 10$ was added. Electrophoresis was performed for $30 \mathrm{~min}$ at $21 \mathrm{~V}$, $300 \mathrm{~mA}, 4^{\circ} \mathrm{C}$. Lastly, the sheets were incubated in a neutralization buffer (0.4 M Tris-Base, $\mathrm{pH}$ 7.5,), followed staining with SybrGreen. Comet analysis was done using OpenComet v.1.3.1 ${ }^{56}$. Global DNA damage (SSB and $\mathrm{DSB})^{57}$ evaluation was determined by measuring tail moment (tail \% DNA $x$ means of head $\mathrm{x}$ tail distance) and representative pictures taken with Olympus IX51 microscope at $\times 200$ magnification. A sampling of at least 50 comets was included in the analysis.

\section{ChIP - qPCR}

Firstly, DNA crosslink was done using $1 \%$ formaldehyde at $\mathrm{R} / \mathrm{T}$ in $1 \times 10^{7}$ cells. Next, at $4{ }^{\circ} \mathrm{C}$, cell lysis buffer was 
added (10 mM Tris- $\mathrm{HCl}, 10 \mathrm{mM} \mathrm{NaCl}$ and $0.5 \% \mathrm{NP}-40$ ), followed by a nuclei lysis buffer $(50 \mathrm{mM}$ Tris- $\mathrm{HCl}, 10 \mathrm{mM}$ EDTA and 1\% SDS). Then, cells were sonicated within optimized cycles. DNA fragments must be ideally with 300 to 500 base pairs (bp). Protein/DNA binding, using a primary antibody, sonicated chromatin, and Magn ChIP protein $\mathrm{A}+\mathrm{G}$ beads (EMD Millipore, USA), was done. Then, consecutive fully washes were carried out using low salt buffer $(0.1 \%$ SDS, $1 \%$ Triton X-100, 2 mM EDTA, $20 \mathrm{mM}$ Tris- $\mathrm{HCl}, \mathrm{pH}=8.1,150 \mathrm{mM} \mathrm{NaCl})$, high salt buffer $(0.1 \%$ SDS, $1 \%$ Triton X-100, $2 \mathrm{mM}$ EDTA, $20 \mathrm{mM}$ Tris-HCl, $\mathrm{pH}=8.1,500 \mathrm{mM} \mathrm{NaCl})$ and $\mathrm{LiCl}$ buffer $(0.25 \mathrm{M} \mathrm{LiCl}, 1 \%$ NP-40, 1 \% Desoxicolate, $1 \mathrm{mM}$ and EDTA, $10 \mathrm{mM}$ Tris). Finally, DNA purification was carried out using a Qiaquick gel extraction kit (Qiagen, Germany) according to the manufacturer's instructions, followed by RT-qPCR. Data is presented using \%Input $\left[100 *\left(2^{\wedge}\left(\mathrm{C}_{\mathrm{T}}\right.\right.\right.$ Raw mean $\left.\left.-\mathrm{C}_{\mathrm{T}}\right)\right]$. Normal mouse IgG and RNA polymerase II protein immunoprecipitation were used as internal controls.

\section{Tissue immunoexpression}

Formalin-fixed paraffin embedded (FFPE) primary tumors from ESCC patients $(n=61)$ were selected from Portuguese Oncology Institute of Porto (IPO-Porto), Portugal after informed patient consent and inserted into tissue microarrays (TMAs). Three representative cores were included for each case. Furthermore, NE samples (n $=20$ ), were obtained from the esophageal margin of radical gastrectomies. This study was approved by the Institutional Review Board of IPO-Porto (CES IPO: 202/ 017).

Immunohistochemistry (IHC) was performed for CAIX, HIF-1 $\alpha$, KDM3A, and KDM6B, as previously described ${ }^{58}$. Semi-quantitative analysis was blindly performed by an expert pathologist classifying extension $(0:<10 \%$; 1 : $10-$ $50 \% ; 2: 50-75 \% ; 3:>75 \%)$ and intensity (0: negative; 1 : weak; 2: moderate; 3 : strong) for each protein. Then, the combination of intensity and extension was done and a final score $\geq 1$ was set to define positive cases.

\section{CAM assay}

Fresh fertilized eggs (PintoBar, Lda, Portugal) were incubated at $37^{\circ} \mathrm{C}$ in a humid environment. After 6 days of embryonic development, a window was opened into the eggshell under aseptic conditions. On day 10, Kyse-410 cells suspension in growth factor-reduced Matrigel (BD Biosciences) were seeded on CAM. Then, on day 13, a treated group, randomly selected, received IOX1 $50 \mu \mathrm{M}$ whereas a control group received only $1 \%$ DMSO in complete RPMI-1640. After 24h, CAM was irradiated with 2 Gy. Lastly, on day 17, tumors were dissected and included in a paraffin block. Microtumor images were obtained on day 13 ( $0 \mathrm{~h}$ of treatments) and at day 17 (72 h of treatment). Relative perimeter in in ovo was assessed using CellSens software (version V0116, Olympus). Ex ovo pictures were obtained for blood vessels counting using Image J software.

Immunostaining of microtumors' sections was evaluated through a quantitative method using GenASIS software (Applied Spectral Imaging, ASI). Staining's evaluation was performed as described in the tissue immunoexpression subsection.

\section{Statistics}

Non-parametric tests (Kruskal-Wallis or Mann-Whitney $\mathrm{U}$ test) among groups with Bonferroni's correction were used to compare different conditions in in vitro assays through GraphPad Prism version 6.0. IHC results were analyzed by Pearson's chi-square or Fisher's exact test, using the SPSS 25.0 software. All results are shown as the mean \pm $\mathrm{SD}$ for each group. For each analysis, $\mathrm{p}$ values were considered significant when inferior to $0.05\left({ }^{*} p<0.05 ;{ }^{* *} p<\right.$ $0.01 ;{ }^{* * * *} p<0.001 ;{ }^{* * * * * *} p<0.0001$ ).

\section{Acknowledgements \\ Cell lines were kindly provided by Prof. Fátima Baltazar, PhD, from Life and Health Sciences Research Institute, ICVS-3B's, Braga, Portugal (Kyse-30 and Kyse-410), cell line was kindly provided by Prof. Zdenko Herceg, PhD, from IARC - International Agency for Research on Cancer, World Health Organization, Lyon, France (OE21) and Prof. Raquel Almeida, PhD, from IPATIMUP/i3S, Porto, Portugal (Het-1A). This study was partially supported by Research Center IPO-Porto: PI 27-CI-IPOP-FB-CBEG and ESTIMA-NORTE-01- 0145-740 FEDER-000027. V.M.G. received a junior researcher contract from POCI-01-0145-FEDER-29043 (EpiMarkGermCell): development of novel prognostic and predictive epigenetic biomarkers for malignant testicular germ cell tumors.}

\section{Author details}

${ }^{1}$ Cancer Biology \& Epigenetics Group - Research Center, Portuguese Oncology Institute of Porto (CI-IPOP), Porto, Portugal. ${ }^{2}$ Medical Physics, Radiobiology and Radiation Protection Group - Research Center, Portuguese Oncology Institute of Porto (CI-IPOP), Porto, Portugal. ${ }^{3}$ Departments of Medical Physics, Portuguese Oncology Institute of Porto, Porto, Portugal. ${ }^{4}$ Departments of Pathology, Portuguese Oncology Institute of Porto, Porto, Portugal. ${ }^{5}$ Department of Pathology and Molecular Immunology, Institute of Biomedical Sciences Abel Salazar - University of Porto (ICBAS-UP), Porto, Portugal

\section{Conflict of interest}

The authors declare that they have no conflict of interest.

\section{Publisher's note}

Springer Nature remains neutral with regard to jurisdictional claims in published maps and institutional affiliations.

Supplementary Information accompanies this paper at (https://doi.org/ 10.1038/s41419-020-03279-y).

Received: 8 April 2020 Revised: 30 October 2020 Accepted: 3 November 2020

Published online: 14 December 2020

\section{References}

1. Bray, F. et al. Global cancer statistics 2018: GLOBOCAN estimates of incidence and mortality worldwide for 36 cancers in 185 countries. CA: Cancer J. Clinicians. https://doi.org/10.3322/caac.21492 (2018). 
2. Ferlay, J. et al. Cancer incidence and mortality worldwide: sources, methods and major patterns in GLOBOCAN 2012. Int. J. Cancer 136, E359-E386 (2015).

3. Arnold, M., Soerjomataram, I., Ferlay, J. \& Forman, D. Global incidence of oesophageal cancer by histological subtype in 2012. Gut 64, 381-387 (2015)

4. Engel, L. S. et al. Population attributable risks of esophageal and gastric cancers. J. Natl Cancer Inst. 95, 1404-1413 (2003).

5. Alsop, B. R. \& Sharma, P. Esophageal cancer. Gastroenterol. Clin. North Am. 45, 399-412 (2016).

6. Meves, V., Behrens, A. \& Pohl, J. Diagnostics and early diagnosis of esophageal cancer. Viszeralmedizin 31, 315-318 (2015).

7. Shah, R. D., Cassano, A. D. \& Neifeld, J. P. Neoadjuvant therapy for esophageal cancer. World J. Gastrointest. Oncol. 6, 403-406 (2014).

8. Napier, K. J., Scheerer, M. \& Misra, S. Esophageal cancer: a Review of epidemiology, pathogenesis, staging workup and treatment modalities. World. J. Gastrointest. Oncol. 6, 112-120 (2014).

9. Napier, K. J., Scheerer, M. \& Misra, S. Esophageal cancer: a review of epidemiology, pathogenesis, staging workup and treatment modalities. World J. Gastrointest. Oncol. 6, 112-120 (2014).

10. Vaupel, P. Hypoxia and aggressive tumor phenotype: implications for therapy and prognosis. Oncologist 13, 21-26 (2008).

11. Xia, X. B. \& Kung, A. L. Preferential binding of HIF-1 to transcriptionally active loci determines cell-type specific response to hypoxia. Genome Biol. 10, 12 (2009).

12. Rockwell, S., Dobrucki, I. T., Kim, E. Y., Marrison, S. T. \& Vu, V. T. Hypoxia and radiation therapy: past history, ongoing research, and future promise. Curr. Mol. Med. 9, 442-458 (2009).

13. Peerlings, J. et al. Hypoxia and hypoxia response-associated molecular markers in esophageal cancer: a systematic review. Methods 130, 51-62 (2017).

14. Ogawa, K. et al. Clinical significance of HIF-1alpha expression in patients with esophageal cancer treated with concurrent chemoradiotherapy. Anticancer Res. 31, 2351-2359 (2011)

15. Muz, B., de la Puente, P., Azab, F. \& Azab, A. K. The role of hypoxia in cancer progression, angiogenesis, metastasis, and resistance to therapy. Hypoxia (Auckl.) 3, 83-92 (2015).

16. Maxwell, P. H. et al. Hypoxia-inducible factor-1 modulates gene expression in solid tumors and influences both angiogenesis and tumor growth. Proc. Natl Acad. Sci. U. S. A. 94, 8104-8109 (1997).

17. Horsman, M. R. \& Overgaard, J. The impact of hypoxia and its modification of the outcome of radiotherapy. J. Radiat. Res. 57, i90-i98 (2016).

18. Hall, E. J. \& Giaccia, A. J. Radiobiology for the Radiologist 7th edn, Vol. II 432-447 (Wolters Kluwer Health/Lippincott Williams \& Wilkins, 2012).

19. Tanaka, N. et al. Expression of carbonic anhydrase 9, a potential intrinsic marker of hypoxia, is associated with poor prognosis in oesophageal squamous cell carcinoma. Br. J. Cancer 99, 1468-1475 (2008).

20. Melvin, A. \& Rocha, S. Chromatin as an oxygen sensor and active player in the hypoxia response. Cell Signal 24, 35-43 (2012).

21. Perez-Perri, J. I., Acevedo, J. M. \& Wappner, P. Epigenetics: new questions on the response to hypoxia. Int J. Mol. Sci. 12, 4705-4721 (2011).

22. Jaenisch, R. \& Bird, A. Epigenetic regulation of gene expression: how the genome integrates intrinsic and environmental signals. Nat. Genet. 33(Suppl), 245-254 (2003).

23. Hancock, R. L., Dunne, K., Walport, L. J., Flashman, E. \& Kawamura, A. Epigenetic regulation by histone demethylases in hypoxia. Epigenomics 7, 791-811 (2015).

24. Tsai, Y. P. \& Wu, K. J. Epigenetic regulation of hypoxia-responsive gene expression: focusing on chromatin and DNA modifications. Int. J. Cancer 134, 249-256 (2014).

25. Ramachandran, S., lent, J., Gottgens, E. L., Krieg, A. J. \& Hammond, E. M. Epigenetic Therapy for Solid Tumors: Highlighting the Impact of Tumor Hypoxia. Genes (Basel) 6, 935-956 (2015).

26. Yang, J. et al. In Hypoxia and Consequences from Molecule to Malady Vol. 1177 Annals of the New York Academy of Sciences (eds Peers, C., Haddad, G. G. \& Chandel, N. S.) 185-197 (New York Academy of Sciences, New York, 2009).

27. Hoffmann, I. et al. The role of histone demethylases in cancer therapy. Mol. Oncol. 6, 683-703 (2012).

28. Morera, L., Lubbert, M. \& Jung, M. Targeting histone methyltransferases and demethylases in clinical trials for cancer therapy. Clin. Epigenetics 8, 57 (2016).

29. $\mathrm{Hu}, \mathrm{Q}$. et al. IOX1, a JMJD2A inhibitor, suppresses the proliferation and migration of vascular smooth muscle cells induced by angiotensin $\|$ by regulating the expression of cell cycle-related proteins. Int. J. Mol. Med. 37, 189-196 (2016)
30. Li, X. \& Dong, S. Histone demethylase JMJD2B and JMJD2C induce fibroblast growth factor 2: mediated tumorigenesis of osteosarcoma. Med. Oncol. 32, 53 (2015).

31. Salminen, A., Kaarniranta, K. \& Kauppinen, A. Hypoxia-Inducible histone lysine demethylases: impact on the aging process and age-related diseases. Aging Dis. 7, 180-200 (2016).

32. Lamarche, B. J., Orazio, N. I. \& Weitzman, M. D. The MRN complex in doublestrand break repair and telomere maintenance. FEBS Lett. 584, 3682-3695 (2010).

33. Radhakrishnan, S. K. \& Lees-Miller, S. P. DNA requirements for interaction of the C-terminal region of Ku80 with the DNA-dependent protein kinase catalytic subunit (DNA-PKcs). DNA Repair (Amst.) 57, 17-28 (2017).

34. Fattah, F. J. et al. A role for XLF in DNA repair and recombination in human somatic cells. DNA Repair (Amst.) 15, 39-53 (2014).

35. Abbas, G. \& Krasna, M. Overview of esophageal cancer. Ann. Cardiothorac. Surg. 6, 131-136 (2017).

36. Campbell, N. P. \& Villaflor, V. M. Neoadjuvant treatment of esophageal cancer. World J. Gastroenterol. 16, 3793-3803 (2010).

37. Koukourakis, M. I. et al. Hypoxia inducible factor (HIF-1a and HIF-2a) expression in early esophageal cancer and response to photodynamic therapy and radiotherapy. Cancer Res. 61, 1830-1832 (2001).

38. Yang, J. et al. Role of hypoxia-inducible factors in epigenetic regulation via histone demethylases. Ann. N. Y. Acad. Sci. 1177, 185-197 (2009).

39. Hopkinson, R. J. et al. 5-Carboxy-8-hydroxyquinoline is a broad spectrum 2oxoglutarate oxygenase inhibitor which causes iron translocation. Chem. Sci. 4, 3110-3117 (2013)

40. Mimura, I. et al. Dynamic change of chromatin conformation in response to hypoxia enhances the expression of GLUT3 (SLC2A3) by cooperative interaction of hypoxia-inducible factor 1 and KDM3A. Mol. Cell Biol. 32, 3018-3032 (2012).

41. Wade, M. A. et al. The histone demethylase enzyme KDM3A is a key estrogen receptor regulator in breast cancer. Nucleic Acids Res. 43, 196-207 (2015).

42. Ramadoss, S. et al. Lysine-specific demethylase KDM3A regulates ovarian cancer stemness and chemoresistance. Oncogene 36, 1537-1545 (2017).

43. Osawa, T. et al. Inhibition of histone demethylase JMJD1A improves antiangiogenic therapy and reduces tumor-associated macrophages. Cancer Res. 73, 3019-3028 (2013)

44. Rath, B. H., Waung, I., Camphausen, K. \& Tofilon, P. J. Inhibition of the histone H3K27 demethylase UTX enhances tumor cell radiosensitivity. Mol. Cancer Therapeutics 17, 1070-1078 (2018).

45. Yuan, $\mathrm{X}$. et al. KDM4C, a H3K9me3 histone demethylase, is involved in the maintenance of human ESCC-initiating cells by epigenetically enhancing SOX2 expression. Neoplasia 18, 594-609 (2016).

46. Sun, X. et al. Oncogenic features of PHF8 histone demethylase in esophageal squamous cell carcinoma. PLOS ONE 8, e77353 (2013).

47. Bayo, J. et al. Jumonji inhibitors overcome radioresistance in cancer through changes in H3K4 methylation at double-strand breaks. Cell Rep. 25, 1040-1050. e1045 (2018).

48. Hoshino, I. et al. Genome-wide ChIP-seq data with a transcriptome analysis reveals the groups of genes regulated by histone demethylase LSD1 inhibition in esophageal squamous cell carcinoma cells. Oncol. Lett. 18, 872-881 (2019).

49. Cai, Y., Fu, X. \& Deng, Y. Histone demethylase JMJD1C regulates esophageal cancer proliferation Via YAP1 signaling. Am. J. Cancer Res. 7, 115-124 (2017).

50. Sun, L. L. et al. Histone demethylase GASC1, a potential prognostic and predictive marker in esophageal squamous cell carcinoma. Am. J. Cancer Res. 3, 509-517 (2013).

51. Li, S. H. et al. The prognostic significance of histone demethylase UTX in esophageal squamous cell carcinoma. Int. J. Mol. Sci. 19, https://doi.org/ 10.3390/ijms19010297 (2018).

52. Ardyanto, T. D., Osaki, M., Tokuyasu, N., Nagahama, Y. \& Ito, H. CoCl2induced HIF-1 alpha expression correlates with proliferation and apoptosis in MKN-1 cells: A possible role for the PI3K/Akt pathway. Int. J. Oncol. 29, 549-555 (2006).

53. Barros-Silva, D. et al. MicroRNA-27a-5p regulation by promoter methylation and MYC signaling in prostate carcinogenesis. Cell Death Dis. 9, 167 (2018).

54. Ramalho-Carvalho, J. et al. A multiplatform approach identifies miR-152-3p as a common epigenetically regulated onco-suppressor in prostate cancer targeting TMEM97. Clin. Epigenetics 10, https://doi.org/10.1186/s13148-018-04752 (2018). 
55. Zhang, Y., Hu, K., Beumer, J. H., Bakkenist, C. J. \& D'Argenio, D. Z. RAD-ADAPT: software for modelling clonogenic assay data in radiation biology. DNA Repair (Amst.) 52, 24-30 (2017).

56. Gyori, B. M., Venkatachalam, G., Thiagarajan, P. S., Hsu, D. \& Clement, M. V. OpenComet: an automated tool for comet assay image analysis. Redox Biol. 2 , 457-465 (2014).
57. Cortés-Gutiérrez, E. I. et al. Evaluation of DNA single and double strand breaks in women with cervical neoplasia based on alkaline and neutral comet assay techniques. J. Biomed. Biotechnol. 2012385245 (2012).

58. Carneiro, I. et al. Expression of EMT-related genes CAMK2N1 and WNT5A is increased in locally invasive and metastatic prostate cancer. J. Cancer 10, 5915-5925 (2019). 